\title{
La cerámica almohade en verde y manganeso de la meseta
}

\author{
Manuel Retuerce Velasco * \\ Antonio de Juan García ***
}

Con el presente trabajo se trata de dar a conocer una selección de algunas de las más notables piezas cerámicas almohades de la submeseta sur (ver Apéndice I). Procedentes de las excavaciones arqueológicas de Calatrava la Vieja y Alarcos (Prov. de Ciudad Real), todas ellas se hallan decoradas con una combinación vidriada policroma en blanco/verde y negro (B-3-a-I) (RETUERCE \& ZOZAYA, 1986: 98-1 I2; AZUAR, 1989: 321-324; RETUERCE, 1997a). Producto de los alfares locales de ambas localidades (ver Apéndice II), la cronología de todos los ejemplares que se muestran es bastante precisa, pues se encuadra entre los veranos de 1195 y 1212 . Exactamente los 17 años que transcurren entre las batallas de Alarcos y de las Navas de Tolosa, fechas que enmarcan el corto período de la ocupación almohade de las tierras de la Meseta y, en concreto, de Alarcos y Calatrava la Vieja.

Todas las piezas que aquí se presentan fueron encontradas en unos claros contextos arqueológicos de época almohade. Las de Calatrava la Vieja formaban parte de un conjunto de materiales que rellenaba el interior de la torre $n^{\circ}$ $X X V I I$ del recinto de la medina (Fig. I), siendo resultado del pillaje sufrido por la ciudad tras ser conquistada la noche del 30 de junio de 1212 por las tropas cruzadas mandadas por Alfonso VIII de Castilla (RETUERCE, 1995a; 1995b; 1997b).
Los ejemplares de Alarcos fueron encontrados en los niveles almohades del castillo (Fig. 2), anteriores a su definitiva conquista castellana el día 2 de julio de ese mismo año de 1212 (JUAN, CABALLERO \& FERNÁNDEZ, 1995; 1996).

Se trata de un lote casi único en la arqueología almohade, pues en esta época el sistema decorativo en "verde/manganeso" sólo se ha constatado en muy pocos ejemplares y en escasos fragmentos. Así, hasta el momento, además de las piezas que aquí presentamos, ejemplares completos sólo se han encontrado en muy contados lugares. En Mallorca figura en diversos ataifores del tipo III (ROSSELLÓ, 1987: 135). Hasta ahora, también se ha constatado en algunas localidades de Andalucía: Córdoba ', Priego de Córdoba, donde incluso se ha excavado un horno (CARMONA, 1994, THIRIOT, 1995: 29, fig. 7) que, entre otras, producía este tipo de manufactura en época almohade ${ }^{2}$, Andújar (CASTILLO, 1991: 286, fig. I I) y Málaga. R. Puertas ( 1985: n I, figs. I.I y 12.1) fecha esta pieza con decoración en época califal. Por contra, M. Acién \& alii (1995: 126, tipo 153.3) lo fechan como almohade del siglo XIII-. Diversos fragmentos han aparecido también en Denia (VV. AA., 1988: 39; GISBERT, 1990: 75) y Jerez de la Frontera (FERNÁNDEZ, 1986: fig. 54.1 y 2). Por último, habría que apuntar la posibilidad de que este sistema

\footnotetext{
* Universidad SEK de Segovia.

*** Escuela-Taller de Alarcos. Ap. 203. 13080-CIUDAD REAL.

I Información verbal facilitada por Manuel Acién Almansa.

2 Información verbal facilitada por Rafael Carmona Ávila. El estudio de la producción en verde-manganeso almohade encontrada en este alfar será objeto de una comunicación por parte de este investigador en Octubre de 1997 en Tondela (Portugal).
} 
decorativo sea también el que se presenta en una pieza encontrada en Teruel -con un diseño trenzado que ocupa toda la superficie interior(WV. AA., 1988: n 91).

A diferencia de lo que por el momento parece suceder en casi todos los ámbitos de la geografía andalusí de época almohade, en donde este clásico sistema decorativo vidriado -un fondo blanco sobre el que se desarrolla una decoración en verde enmarcada con trazos negros- apenas muestra ejemplos -sólo cabría apuntar la excepción de Andalucía, donde empiezan a aparecer piezas de esa fase-, en el área en torno a Calatrava la Vieja y Alarcos no sólo está presente -también han aparecido fragmentos así decorados en el cercano castillo de Benavente- sino que aparece con una relativa abundancia.

Este hecho, como se verá, no deja de ser extraño, sobre todo cuando esta región, aunque en vanguardia frente al Reino de Castilla, no dejaba de ser marginal en el inmenso mapa que comprendió el Imperio almohade. De todas formas, la presencia de todo tipo de productos y materiales, excelentes y casi únicos, de este período en tierras de la Meseta es una realidad ya constatada, que viene a señalar la pujanza de determinadas poblaciones que habitaban en la frontera. Así, de momento y en el caso concreto de Calatrava la Vieja, se ha documentado una producción local de piezas cerámicas decoradas en "reflejo dorado" (ZOZAYA; RETUERCE \& APARICIO, 1995), una producción propia de vidrios (RONTOMÉ, 1995: 266-267, n० | I 2 y | | 3), una importación de productos alimenticios - pescado del área del Estrecho- (ROSELLÓ \& MORALES, 1991), etc.

\section{ESTUDIO}

En primer lugar, hay que destacar que por el momento todas las piezas de época almohade que en Calatrava la Vieja y Alarcos se muestran decoradas mediante un vedrío policromo en blanco/verde y negro (B-3-a-I) lo hacen sobre un mismo tipo de soporte cerámico (Ver apéndice I). Exactamente, se presenta en piezas que se corresponden con ataifores del tipo A.25 (RETUERCE, 1997a). Y a la vez, se trata de unos ejemplares de ataifores que siempre que se decoran lo hacen empleando dicho sistema decorativo. En definitiva, tanto el continente cerámico como el sistema decorativo son absolutamente exclusivos entre si.

\section{EL TIPO CERÁMICO: A.25}

Por las razones expuestas, nos parece importante definir las características propias del tipo A.25, perteneciente a la Forma $A$-a ella se adscriben piezas abiertas como ataifores, safas, escudillas, platos, fuentes, etc.- (RETUERCE, 1997a).

Se trata de un recipiente abierto de mediano y gran tamaño. Posee un fuerte anillo de solero de sección diagonal y normalmente de ángulos rectos, aunque no faltan ejemplos de anillos diagonales y redondeados. Presenta paredes rectas que, tras una pronunciada carena curva, enlazan con un borde vertical o apenas exvasado, ligeramente curvo al exterior y recto al interior. Termina con un característico labio que posee una pequeña moldura redonda al exterior y una segunda, de mayor tamaño y más apuntada, al interior. Con vedrío. Con o sin decoración.

Del análisis de todos los ejemplares diferenciados del tipo A.25 -ataifores-, se ve que en ellos la pasta suele ser de color naranja, rosado o rojo. Siendo gris en aquellas piezas que presentan un vedrío verde por ambas caras. Por otro lado, la pasta incluye pequeñas y medianas intrusiones calizas. Mientras que el diámetro del borde está comprendido entre los 25 y 38 $\mathrm{cm}$., el de la base se encuadra entre los 8,5 y 13 $\mathrm{cm}$. y la altura total oscila entre los 10 y $15,5 \mathrm{~cm}$.

En cuanto al acabado, son pocas la piezas que poseen el vedrío sólo por la superficie interior; en este caso, el color más frecuente es el verde, aunque no faltan ejemplares con el blanco o el pardo; no dándose, por el contrario, el melado. En las piezas con vidriado por ambas superficies, excepto en un único caso de vedrío verde oscuro por ambas caras, el color de vedrío que se presenta con exclusividad al exterior es el melado; siempre de muy mala calidad y manifestado sólo en la aplicación de una ligera capa que apenas es perceptible. 
Por la superficie interior, excepto el caso mencionado en verde, todas las piezas de este tipo de ataifor llevan o bien un vedrí blanco estannífero de un tono muy azulado y sucio, casi transparente, que incluso deja ver la pasta rosada del soporte en algunas zonas de su superficie, o bien una combinación decorativa del mismo matiz de blanco como fondo junto al verde y al negro, que forman el diseño decorativo propiamente dicho (B-3-a-I). En este caso, el negro presenta siempre una coloración muy violácea muy cercana al morado, con una tonalidad muy aguada. El verde es muy mate, claro, apenas sin brillo y casi celeste, y sirve para rellenar el diseño decorativo compuesto por el color negro. Por aparecer fragmentadas en el borde, muchas piezas sólo conservan al interior el vedrío blanco. Pese a ello, estamos seguros de que, si no todos, la mayoría de los ejemplares tendrían este vedrío blanco como fondo de una decoración en verde/negro-morado, según se puede ver en aquellas otras que se han conservado más o menos completas. En bastantes de los ejemplares conservados el vedrío interior vierte descuidadamente al exterior del borde.

Por otro lado, la parte baja del exterior de las piezas -concretamente el anillo de solero- no está nunca vidriada. En las piezas de este tipo son bastante normales los orificios que denotan un lañado, lo que indica que se trataba de piezas que, por lo menos y por muy diversos motivos, eran apreciadas por su propietario. En este mismo sentido, también es frecuente la presencia de pequeñas perforaciones aisladas que traspasan totalmente el grosor de las piezas y que no son lañas, pues también se presentan en ejemplares enteros y sin fragmentaciones. Normalmente se localizan en el anillo de solero, pero también en el mismo borde, como muy bien se puede ver en la pieza $n^{\circ}$ I. Este hecho nos hace pensar que todas estas piezas se guardaban colgadas en la pared, poseyendo entonces una doble función: como elemento del servicio de mesa y como un objeto de adorno de carácter profiláctico o amuleto, cuando tenían el uso anterior.

En este sentido, conviene señalar que además de su característica forma de cuenco recuerdo de la bóveda celeste-, las piezas que se encuadran dentro del tipo A.25, si se exceptúan los ejemplares ornamentados en "reflejo dorado", son las únicas Formas abiertas -ataifores, jofainas, safas, etc.- de la fase almohade que en Calatrava la Vieja y Alarcos aparecen con una decoración. Decoración que, según veremos, se desarrolla con unos motivos y diseños totalmente cargados de simbolismo.

Por último, debemos hacer notar que uno de los pocos ejemplares almohades en verde $y$ manganeso aparecido fuera de las tierras meseteñas se encuadra dentro del tipo A.25 diferenciado en la Meseta. Nos referimos a uno de los fragmentos encontrados en Andújar (CASTILLO, | 99 I: fig. I I c), que presenta un perfil exactamente igual al de las piezas del valle del Guadiana. Por otro lado, por lo que se puede apreciar en los dibujos de algunas de las piezas andujareñas, pensamos que también en lo que se refiere a los diseños decorativos y a la distribución de los colores, se trata de una producción muy cercana a la meseteña (CASTILLO, 1991: fig. I la, b, c y e). Por otro lado, ello no debiera resultar extraño si observamos la relativa proximidad de Andújar con los yacimientos meseteños del Guadiana medio.

\section{EL SISTEMA DECORATIVO: VERDE-MAN- GANESO (B-3-A-I)}

Según ya se ha mencionado, se trata de un sistema que tanto en Calatrava la Vieja como en Alarcos se manifiesta con unas piezas excepcionales. Por otro lado, el sistema decorativo en "verde y manganeso", por el momento, es la única combinación policroma simple que se da en la Meseta durante el período africano.

Igual que sucede en Mallorca a principios del siglo XIII (ROSSELLÓ, 1987: 135), en la zona en torno a Calatrava la Vieja y Alarcos, la única área de la Meseta a la que por ahora nos podemos referir, también se da un "renacimiento" de esta combinación polícroma. Sin embargo, el soporte concreto donde aparece -siempre en piezas de la Forma A (ataifores, etc.)- varía, aun perteneciendo a una misma Familia A.Ill. Según ya se ha dicho, mientras que en Mallorca se presenta en alguna variante de los ataifores del tipo III (ROSSELLÓ, 1987: I35), en el área mencio- 
nada de la Meseta son únicamente las piezas del tipo A.25 las que presentan este sistema decorativo.

Observando las piezas almohades de Calatrava y Alarcos se aprecia que el empleo del término "renacimiento" es igualmente aplicable para la Meseta, pues si bien la combinación del blanco/verde-negro es muy evidente -con la que se revive la tradición omeya en su empleo y disposición- existen también bastantes diferencias con la antigua producción de los siglos $X$ y $X I$. En lo referente a los colores aparecen con unas características muy diferentes a como se presentaban durante el período omeya. En cuanto a la viveza de los colores las diferencias son notables. Así, en las piezas omeyas los colores son muy vivos y brillantes. Por el contrario, en las almohades su viveza es bastante menor, dando una sensación general de poseer un cromatismo muy "aguado" o licuado. De este modo, en estas últimas piezas el vedrío blanco estannífero del fondo es de un color azulado casi transparente y deja ver en algunas partes de la superficie la pasta rosada del soporte; el verde es muy claro y casi mate; y el negro, muy violáceo.

Por otro lado, si bien aún perdura la ordenación espacial, el esquematismo y la expresividad de los temas decorativos en general es ahora casi absoluto, muy lejos del realismo de las piezas omeyas. Está claro que además de incorporar novedades de gusto muy oriental (pieza $\mathrm{n}^{\circ}$ 6), se participa de unas antiguas fuentes temáticas y perdura la ordenación espacial omeya (piezas $n^{\circ} 1-5$ ), si bien ha desaparecido el abigarramiento, el naturalismo y el perfeccionismo de aquel período, viniendo a ser sustituido por una mayor simplicidad y una gran abstracción, llevada hasta el máximo grado de expresividad, de la idea que se pretendía plasmar. De este modo, se puede decir que el renacimiento que en al-Andalus se produce a caballo de los siglos XII y XIII de la técnica decorativa del "verde/ manganeso" significa la sustitución de un realismo omeya por un expresionismo almohade, el cual vino a servir de eslabón con la técnica y diseños de la que posteriormente sería importante producción bajomedieval de la cerámica de Teruel, Paterna, Cataluña, Castilla, etc.

\section{MOTIVOS DECORATIVOS:}

Pasando ahora a los motivos decorativos, si bien casi todos ellos ( $n^{\circ}$ I-5) beben en las fuentes temáticas omeyas, ha desaparecido el abigarramiento, el naturalismo y el perfeccionismo del período anterior, siendo sustituido por una mayor simplicidad en los trazos y una gran abstracción conceptual, que es llevada hasta el máximo y, como veremos, con distintas gradaciones, en el desarrollo de la idea que en origen se pretendía plasmar. Todo ello es resultado de una clara evolución de los conceptos temáticos de origen omeya, que viene a significar toda una transformación y un cambio hacia lo que se podría considerar como un claro expresionismo almohade.

No sabemos si el usuario concreto de todos estos recipientes era consciente del fuerte simbolismo que estaba reflejado en ellos. Pero lo que sí que parece seguro es que de algún modo el alfarero de todas las piezas que aquí presentamos o el modelo al que trata de copiar se tuvo que inspirar en fuentes más o menos eruditas para establecer las diferentes figuras simbólicas.

Aun corriendo bastantes riesgos -el campo de la interpretación siempre tiene mucho de subjetivo-, no queremos limitarnos a realizar una mera y común descripción de los motivos que aparecen reflejados en cada uno de los ataifores que mostramos. De este modo, además de la pertinente exposición de las figuras decorativas, nos atrevemos a tratar de acercarnos al más o menos hipotético mensaje que en origen se intentaba transmitir al usuario de estos recipientes.

\section{Diseño radial en movimiento: flores de loto/estrella}

Aparte de las diferencias tipológicas de los recipientes y de las posibles en cuanto a la consistencia y viveza cromática, es el aspecto de la ordenación espacial de los temas decorativos en blanco/verde y negro uno de los que con más claridad distinguen la producción meseteña de la mallorquina durante la fase almohade. A la sencillez, expresividad y esquematismo de los 
temas florales presentes en Calatrava y Alarcos se contrapone el tan desarrollado geometrismo de los mallorquines (ROSSELLÓ, 1978).

De este modo, en la pieza $n^{\circ}$ | estamos ante un diseño radial (RETUERCE \& ZOZAYA, 1986: 1 12) de cuatro flores de loto que, con un origen central común, giran al unísono, como un molinillo en sentido contrario a las agujas del reloj. Se viene a dar la impresión de que desde el fondo de la bóveda celeste -el propio fondo del ataifor- en movimiento, surgieran cuatro flores de loto que, a causa de ese mismo y veloz movimiento giratorio hacia la izquierda son obligadas a doblarse por la parte más alejada del eje central. El precedente omeya "clásico" es más abigarrado -con ocho flores de loto continuas, en una pieza procedente de Medina al-Zahra (RETUERCE \& ZOZAYA, 1986: fig. 31.6)- y menos esquemático que el desarrollado en el ejemplar almohade.

El ejemplar calatravo, sin embargo y a pesar de albergar una esquematización del motivo clásico, resulta ser, de entre las piezas almohades que portan el mencionado motivo, la más cercana a los cánones del clasicismo, sobre todo si lo comparamos con la absoluta sintetización expresionista que se muestra en los ejemplares $n^{\circ} 2$ y 3 , de Alarcos. En estos últimos, el movimiento giratorio que formaban las cuatro flores de loto se ha transformado ya en una estrella de cuatro puntas que está en un continuo giro de izquierda a derecha.

En un estadio expresionista intermedio se encuentra la pieza $n^{\circ} 2$. En ella, las cuatro flores de loto se han unido por la parte contraria para ir a formar un motivo estrellado en el que apenas se aprecia el motivo vegetal primitivo: volutas a ambos lados de cada una de las flores de loto. La extrema abstracción se encuentra en la pieza $\mathrm{n}^{\circ} 3$, donde el único recuerdo del origen vegetal de la ahora estrella de cuatro puntas es el festoneado -a modo de hojas batidas por la velocidad del giro- de cada una de las que en principio fueron flores de loto. En ambas piezas alarqueñas, la evocación del eje del giro constante ha quedado fosilizada en el pequeño motivo cruciforme central que se formó por la unión de las cuatro flores de loto originales.
Con la conjunción de la propia forma cóncava del ataifor, las cuatro flores de loto girando alrededor de su centro y su posterior conversión en una estrella giratoria de cuatro puntas, se está tratando de dar un mensaje que quiere hacer recordar al usuario del plato su unión con Dios como creyente. En nuestra opinión, el mensaje podría ser el que a continuación describimos, primero aislando cada una de sus partes y después tratando de explicar todo el conjunto.

La flor de loto es el símbolo de la pureza, "ya que surgiendo de las aguas estancadas, oscuras y pantanosas, no está manchada por ellas. Así, salido de la oscuridad de las aguas sucias, se abre a plena luz, convirtiéndose en el símbolo de la plenitud espiritual del creyente" (CHEVALIER \& GHEERBRANT, 1991: 656). Vienen a representar, por tanto, los cuatro árboles del Paraíso.

Del mismo modo, la estrella en que se convierten las flores de loto viene a ser una "fuente de luz $y$, en particular, del conflicto entre las fuerzas espirituales, o de la luz, y de las fuerzas materiales, o de las oscuras tinieblas" (CHEVALIER \& GHEERBRANT, 1991: 484). En concreto, se trata de la estrella polar, que en cualquier cultura ha venido a representar "el centro orgánico y absoluto del cielo, en torno al cual gira eternamente el firmamento,... por lo que viene a expresar el Centro al que todo se refiere, el Principio de donde todo emana, el Motor que todo lo mueve y el Jefe alrededor del cual gravitan los astros como una corte en torno a su rey" (CHAMPEAUX \& STERCKX, 1984: 26-27).

A través de la simbiosis de los cuatro árboles del Paraíso convertidos a su vez en la estrella polar, que en apariencia giran y gira, respectivamente de izquierda a derecha, se está tratando de reflejar el sagrado Cielo -la bóveda celeste representada por la propia forma cóncava del plato-. Sin embargo, allí, en el Paraíso, las cuatro flores de loto -los cuatro árboles de Paraíso- (pieza $\mathrm{n}^{\circ} \mathrm{I}$ ), que se convierten en la estrella polar (piezas $n^{\circ} 2$ y 3 ) están inmóviles. Es el usuario del plato o creyente el que con su contemplación gira alrededor del Paraíso -donde se sitúan los 4 lotos/árboles y la inmóvil estrella polar-, que se sitúa en el centro de la bóveda celeste/ataifor. Sin embargo, el artesano, por 
las evidentes dificultades figurativas y con el fin de reflejar la idea de la participación del fiel musulmán en el Paraíso, no tenía más remedio que hacer aparentar dicho movimiento contemplativo en los elementos simbólicos; cuando en realidad éstos, por su propia naturaleza de evocadores de la idea de Dios, motor del Universo, son consustancialmente estáticos.

Esta misma forma de adoración giratoria a Dios por parte de la comunidad musulmana se ve reflejada en la tierra en su lugar más sagrado: la Ka'aba de La Meca. Este es el lugar en el que los fieles musulmanes, en su rito de unión con Alá, giran alrededor de la roca sagrada, -el Tạwāf-, en el mismo sentido que lo hace el usuario del ataifor -que contempla la bóveda celeste donde se sitúan los cuatro árboles del Paraíso y la inmóvil estrella polar. De este modo, el fiel creyente, al cumplir con el ritual de circunvalar la piedra sagrada por todas sus partes, se convierte él mismo en una de sus partes: participa de Dios. Es así que según la tradición islámica, la Ka'aba es el lugar más alto de la tierra, pues la estrella polar prueba que se encuentra exactamente debajo del centro del cielo (ELIADE, 1964: 95).

\section{Diseño radial estático: flores de loto}

El mismo diseño radial, pero estático, es el que se presenta en la pieza $n^{\circ} 4$. A partir de un mismo eje central generador nacen los cuatro árboles de la vida en forma de flores de loto en la plenitud del desarrollo del capullo, momentos antes de su total apertura. Entre ellos, otros cuatro capullos de menor tamaño. Del mismo modo la pieza $n^{\circ} 5$, con un gran estatismo, tiene un diseño central generador de cuatro flores de loto abstractas. Su precedente omeya se encuentra en algunas piezas almerienses y de Medina alZahra (RETUERCE \& ZOZAYA, 1986: fig. 29.6 y 7).

\section{Diseño antropomorfo:}

Aparte de sus grandes dimensiones y de haberse conservado completa, la pieza $n^{\circ} 6$ destaca por su gran contenido simbólico, no exento de determinados detalles que resultan sumamente sugestivos.
Parece estar bastante claro que en la decoración del gran ataifor se quiere reflejar la sumisión de los creyentes a Dios. Éste se manifiesta claramente mediante la representación en el centro del ataifor de Su brazo y de la palma de Su mano derecha, que son los símbolos, respectivamente, "del socorro acordado y de la protección y de la misericordia y de la bendición divina" (CHEVALIER \& GHEERBRANT, 1991: 197 y 682). En definitiva, se está aludiendo también al juramento de fidelidad y alianza -recuérdese la presencia del anillo que ata y une en el dedo meñique- de los creyentes con Alá, el Compasivo, el Misericordioso: "Los que te juran fidelidad, la juran en realidad, a Dios. La mano de Dios está sobre sus manos. Si uno quebranta una promesa la quebranta, en realidad, en detrimento propio. Si, en cambio es fiel a la alianza concertada con Dios, Él le dará una magnífica recompensa". (Corán, 48,0). "Los judíos dicen «La mano de Dios está cerrada»». ¿Que sus propias manos estén cerradas y sean malditos por lo que dicen!. Al contrario, Sus manos están abiertas y Él distribuye Sus dones como quiere". (Corán, 564). "El favor está en la mano de Dios, Que lo dispensa a quien Él quiere". (Corán, 373).

El fervor de los hombres hacia Dios se encuentra representado por las dos aves situadas en el cielo en actitud adorante a los dos lados del brazo misericordioso de Dios: "¿No han visto (los hombres) las aves sujetas (al servicio de Dios) en el aire del cielo?. Sólo Dios las sostiene. Ciertamente, hay en ello signos para gente que cree". (Corán, 1679). "¿Es que no han visto (los hombres) las aves encima de ellos, desplegando y recogiendo las alas?. Sólo el Compasivo las sostiene. Lo ve bien todo". (Corán, 67/9). "... Sujetamos, junto con David, las montañas y las aves para que glorificaran (al Señor)". (Corán, 2 I $_{79}$ ).

De momento, no podemos interpretar los diferentes símbolos que se presentan en el brazo de Alá. De todas formas, éste parece nacer de un nudo que presenta en su vértice una flor de loto -la pureza-. Además de otro nudo y otra flor de loto que figuran en la parte central del brazo, aparece una decoración epigráfica de difícil transcripción. 
Aparte de todo lo mencionado, lo más sorprendente y sugestivo de la decoración que se desarrolla en el ataifor es la aparición en la palma de la mano de Dios de diferentes y muy expresivos rasgos que parecen representar un rostro. ¿La faz de Dios Omnipotente, Compasivo y Misericordioso?. Desde luego, ello puede parecer bastante heterodoxo, pero aprovechando el propio diseño de la palma de la mano figuran con meridiana claridad todos los rasgos de una cara: mentón, dos ojos, nariz y ¿bigotes? Sólo falta la boca. De forma muy expresiva, pensamos que, en efecto, se está representando con todo respeto y con un gran sentimiento de veneración la faz y la mano de Dios Misericordioso: "De Dios son el Oriente y el Occidente. Adondequiera que os volváis, allí está la faz de Dios. Dios es inmenso, omnisciente". (Corán, 2 $2_{15}$ ). "jNo invoques a otro dios junto con Dios!. jNo hay más Dios que Él!. ¡Todo perece salvo Su faz!. jSuya es la decisión!. jY a Él seréis devueltos!". (Corán, 2888). "Pero subsiste la faz, majestuosa y honorable, de tu Señor". (Corán, 5527).

"En principio, en las tres religiones monoteístas, la faz de Dios se relaciona con su esencia, y por eso es imposible contemplarla... Cuando Moisés exclama: «Muéstrate a mí» (Éx. 33|3), expresa por esta llamada su deseo de contemplar la esencia divina. De todos modos el éxtasis -en cuanto muerte virtual- parece, según San Agustín, susceptible de permitir cierta aprehensión de Dios: esto ocurrió a Moisés en el Sinaí y a Pablo al ser raptado al tercer cielo. Semejante visión es una anticipación de la beatitud. La visión cara a cara está reservada a la vida eterna. Los místicos imploran a menudo a Dios suplicándole que les muestre su faz" (CHEVALIER \& GHEERBRANT, 1991: 494-495). En este sentido, ino cabría pensar que la decoración que se plasma en el plato pudo estar influenciada por alguna de las corrientes místicas que en ese momento están floreciendo en al-Andalus?.

\section{CONCLUSIONES}

En definitiva y a modo de resumen, el interés de las piezas meseteñas almohades de Calatrava la Vieja y Alarcos es aún más relevante si se tiene en cuenta la importancia que, antes y después del período africano, el sistema deco- rativo en "verde y manganeso" alcanzó en la cerámica medieval española, y que en opinión de G. Rosselló (1987: I35): "es fundamental en el X y XI; decae y casi desaparece en el Xll; renace tímidamente en el XIII islámico; se traspasa al mundo cristiano a fines del XIII...". Por otro lado, los ejemplares almohades que aquí se presentan vienen a ampliar el panorama geográfico de una producción que hasta el momento ha venido siendo considerada como quasi fantasma, pues, aparte de los ejemplares andaluces que sólo muy recientemente han ido apareciendo y que aún están en proceso de estudio, se limitaba sólo a muy escasos fragmentos y piezas.

Observando todos los ejemplares que mostramos, se aprecia que el empleo para ellos del término renacimiento es perfectamente aplicable, pues si bien la combinación del blanco/verde-negro es muy evidente -reviviendo la tradición omeya en su empleo y disposición-, existen también bastantes diferencias con la antigua producción de los siglos X y XI. Así, en lo referido a la intensidad de los colores, en los ejemplares almohades de ambos yacimientos meseteños éstos son muy fríos, dando una sensación general de un cromatismo muy licuado. $Y$ en lo relativo a los temas decorativos, se muestra una importante evolución hacia el expresionismo en el desarrollo de diseños clásicos de época omeya, acompañada de unas muy interesantes y sugestivas concepciones simbólicas, que en determinados casos estarían inspiradas en las corrientes místicas que se desarrollan en el al-Andalus almohade: simbiosis de las cuatro flores de loto giratorias del Paraíso en una estrella polar, la representación antropomorfa de la faz, mano y brazo de Dios, etc.

Por último y a partir de los análisis litológicos microscópicos y químicos de los componentes minerales existentes en una muestra de piezas decoradas en "verde y manganeso" y en "reflejo dorado" procedentes de Calatrava la Vieja y Alarcos, se ha podido conocer que todas ellas han sido elaboradas en cada uno de los dos yacimientos meseteños con arcillas locales, aunque empleando productos importados para la realización de la decoración, tanto la de "verde y manganeso" como la realizada en "reflejo dorado". 


\section{APÉNDICE I: CATÁLOGO}

$N^{0}$ I: Calatrava la Vieja (Carrión de Calatrava, C.R.): Forma A.25 (RETUERCE, 1997). Ataifor. $\varnothing$ borde: $31,5 \mathrm{~cm}$. $\varnothing$ base: $11,8 \mathrm{~cm}$. Altura: $12,9 \mathrm{~cm}$. Pasta rosada con intrusiones finas de cuarzo y mica. Vedrío por ambas superficies: melado al exterior; blanco/verde y negro al interior. El vedrío exterior es de muy mala calidad y apenas está aplicado. Motivo decorativo vegetal central de cuatro flores de loto en movimiento. Con una perforación cerca del borde que serviría para colgar la pieza. Cód. Acabado-decor.: B-3-a-I. Museo de Ciudad Real: CV-84/C-5/I 25/3008. (RETUERCE, 1995: 248-249, n 92;1997a: nº 70)

No 2: Alarcos (Ciudad Real): Forma A.25 (RETUERCE, 1997). Ataifor. $\varnothing$ borde: $33 \mathrm{~cm}$. $\varnothing$ base: $10,3 \mathrm{~cm}$. Altura: $12,7 \mathrm{~cm}$. Pasta rosada con intrusiones finas de cuarzo y mica. Vedrío por ambas superficies: melado al exterior; blanco/verde y negro al interior. Motivo decorativo vegetal central en forma de estrella que tiene como origen la unión de cuatro flores de loto en movimiento. En cada uno de los campos existentes entre cada una de las flores se dispondría un pequeño motivo circular que daba albergue a dos trazos cruzados. Se conservan los restos de cuatro orificios de lañado. Cód. Acabado-decor:: B-3-a-I. Museo de Ciudad Real: AL-95/AL-33-32। I-I50.

No 3: Alarcos (Ciudad Real): Forma A.25 (RETUERCE, 1997). Ataifor. $\varnothing$ borde: $26 \mathrm{~cm}$. $\varnothing$ base: $8,4 \mathrm{~cm}$. Altura: $10 \mathrm{~cm}$. Pasta rosada con intrusiones finas de cuarzo y mica. Vedrío por ambas superficies: melado al exterior; blanco/verde y negro al interior. Motivo decorativo vegetal central en forma de estrella que tiene como origen la unión de cuatro flores de loto en movimiento festoneadas. Cód. Acabado-decor: B-3a-I. Museo de Ciudad Real: AL-95/AL-33-3219. (VV.AA., 1996: II, 136).

No 4: Calatrava la Vieja (Carrión de Calatrava, C.R.): Forma A.25 (RETUERCE, 1997). Ataifor. $\varnothing$ borde: $31,8 \mathrm{~cm}$. $\varnothing$ base: $9,7 \mathrm{~cm}$. Altura: $13,4 \mathrm{~cm}$. Pasta parda con intrusiones calizas finas. Vedrío por ambas superficies: melado al exterior; blanco/verde y negro al interior. Vedrío exterior muy desvaído, apenas perceptible. Motivo decorativo vegetal central de cuatro flores de loto estilizadas y en forma de almendra. Entre ellas, se disponen otras cuatro más pequeñas. Cód. Acabado-decor: B-3-a-I. Museo de Ciudad Real: CV86/C-5/28I/4463. (RETUERCE, 1997a: n 7I).

No 5: Calatrava la Vieja (Carrión de Calatrava, C.R.): Ataifor. $\varnothing$ borde: $32 \mathrm{~cm}$. $\varnothing$ base: $8,5 \mathrm{~cm}$. Altura: $15,4 \mathrm{~cm}$. Pasta roja con intrusiones finas. Vedrío por ambas superficies: melado al exterior; blanco/verde y negro al interior. Vedrío exterior muy mal aplicado y apenas perceptible. Caída hacia el exterior del vedrío blanco interior. Motivo central de cuatro flores de loto. Cód. Acabado-decor:: B-3-a-I. Museo de Ciudad Real: CV-84/C5/65/3200. (RETUERCE, 1997a: nº 72).
No 6: Alarcos (Ciudad Real): Forma A.25 (RETUERCE, 1997). Ataifor. $\varnothing$ borde: $38 \mathrm{~cm}$. $\varnothing$ base: $12,7 \mathrm{~cm}$. Altura: $15,2 \mathrm{~cm}$. Pasta rosada con intrusiones finas de cuarzo y mica. Vedrío por ambas superficies: melado al exterior con derrame blanco del interior; blanco/verde y negro al interior. Motivo decorativo de gran carga simbólica: en la parte central se muestra un antebrazo y la palma de una mano derecha con un anillo en el dedo meñique, profusamente decorados mediante rasgos muy sintéticos y simplificados de líneas, festones, nudos, epigrafía, etc. A ambos lados del antebrazo y mirando a la palma de la mano se disponen lo que podrían ser dos palomas, trazadas muy sintéticamente. Cód. Acabado-decor:: B-3-a-I. Museo de Ciudad Real: AL-95/AL-33-32 I0-32 I I y AL-95/AL27-26003.

\section{APÉNDICE II: INFORME LITOLÓGICO MICROSCÓPICO}

\author{
Alfredo Aparicio Yagüe*
}

\section{Nomenclatura usada:}

Lm = Longitud media de los cristales aciculares (milímetros). Lmax = Longitud máxima de los cristales aciculares (milímetros). $\varnothing \mathrm{m}=$ Diámetro medio de cristales $\circ$ fragmentos de rocas (milímetros).

$\varnothing \max =$ Diámetro máximo de cristales o fragmentos de rocas (milímetros).

$40 \%=$ Porcentaje del volumen total, que ocupa el mineral o fragmento de roca considerado.

\section{Yacimiento: Calatrava la Vieja (Carrión de Calatrava, Ciudad Real)}

Se estudian un total de cuatro muestras numeradas CV-I, CV-2, CV-3 y CV-4. De ellas las tres primeras muestran decoración verde manganeso y la CV-4 decoración de "reflejo dorado". Todas ellas pertenecen a la cultura almohade con una cronología entre 1195 y 1212.

Descripción de las muestras:

CV-I: Clastos de cuarzo con $\varnothing_{m}=0,1 \mathrm{~m}$ de tipo anguloso y extinción ondulante (30\%). Moscovita en cristales aciculares con $L \max =0,2 \mathrm{~mm}$ ( $10 \%)$. Biotitas oxidadas, en formas aciculares con $\mathrm{Lm}=0,25 \mathrm{~mm}(<\mid \%)$ pero con dimensiones máximas de 0,6 $\mathrm{mm}$.

Fragmentos de rocas como esquistos (Cuarzo + Moscovita + Óxidos) de hasta $3 \mathrm{~mm}$. de diámetro, pizarras con Ømax = I,5 mm y ¿Cuarcitas? (agregados de cuarzo).

La matriz es arcillosa micácea de textura micro-criptocristalina (50\%).

CV-2: Clastos de cuarzo (20\%) con $\varnothing \mathrm{m}=0,12 \mathrm{~mm}$. y $\varnothing \max$ $=0,5 \mathrm{~mm}$. Moscovitas aciculares ( $10-20 \%)$ con $\operatorname{Lmax}=0.20$ $\mathrm{mm}$. Biotitas oxidadas de $\varnothing \mathrm{m}=0,10 \mathrm{~m}(<5 \%)$.

* Museo Nacional de Ciencias Naturales-C.S.I.C. Madrid. 
Restos de rocas pizarrosas (muy frecuentes) de gran tamaño (hasta $2 \mathrm{~mm}$ ), se trata de pizarras sericíticas con microcristales de cuarzo.

Hay fragmentos de otros tipos cerámicos incluidos en esta muestra. Tienen $\varnothing_{\mathrm{m}}=1.5 \mathrm{~mm}$. y son ricos en cuarzo $(\varnothing \mathrm{m}=$ $0,4 \mathrm{~mm} .60 \%$ ), el resto es material arcilloso. Pudiera tratarse de cerámicas hechas con material arenoso que resultaron frágiles y que fueron destruidos y mezclados con materiales mas arcillosos.

La pasta es arcillosa (70-60\%) micro-criptocristalina.

Aunque es similar a la muestra anterior, en composición y textura, se observan pequeñas diferencias, debidas probablemente a variaciones de nivel estratigráfico arcilloso en la barrera de donde se extrajeron las arcillas.

CV-3: Clastos de cuarzo (30\%) con $\varnothing m=0,1 \mathrm{~mm}$ y $\varnothing \max$ $=0,3 \mathrm{~mm}$. Moscovitas aciculares en $\operatorname{Lmax}=0,2 \mathrm{~mm}(10 \%)$, biotitas aciculares oxidadas con $\mathrm{Lmax}=0.2 \mathrm{~mm}(<5 \%)$. Algunos cristales de plagioclasa pequeños $(\varnothing \max =0,05$ $\mathrm{mm}$ ). Hay fragmentos de roca como pizarras sericíticas ( $=0,3 \mathrm{~mm}$.) y granitos (Cuarzo + feldespato) de 0,5 mm.

La pasta es arcillosa micro-criptocristalina (60\%).

Es similar a las muestras anteriores pero bien de diferente nivel estratigráfico de una misma barrera de extracción de la arcilla o bien de una zona muy próxima a aquella de donde se sacaron las otras dos muestras.

CV-4: Clastos de cuarzo pequeños ( $\varnothing \max =0,06$ mm.) (30$40 \%$ ) con $\varnothing \mathrm{m}=0,4 \mathrm{~mm}$. Aciculas de biotita oxidadas con $L \max =0,25 \mathrm{~mm}$. (5\%). No se ven fragmentos de roca (I fragmento de agregado de clorita). La pasta es arcillosa criptocristalina de color oscuro y puede contener carbonatos.

Aparentemente no tiene nada que ver con las barreras donde se extraen las muestras anteriores. No obstante, es posible apuntar que en esta muestra pudo haber alguna influencia de alguna acción antrópica, que no se encuentra en ninguna de las otras -tanto en las que se analizan en este trabajo como en el anterior (ZOZAYA; RETUERCE \& APARICIO, 1995)-. En este momento no podemos discernir cual pudo ser, pero apuntamos las siguientes: ¿la técnica de elaboración?, ¿mayor o menor temperatura en la cocción?, ¿mayor o menor contenido de agua?, ¿mayor o menor presión sobre la arcilla?, etc.

Resumen. Las muestras CV-I CV-2, CV-3 (fragmentos decorados en "verde y manganeso") muestran similares características mineralógicas y texturales salvo algunas pequeñas diferencias. Las tres proceden de los alrededores del mismo yacimiento y probablemente, de una misma barrera. Las diferencias observadas obedecen probablemente a la diferencias existentes en la composición de los niveles arcillosos de la barrera.

La muestra CV-4 (fragmento de decorado en "reflejo dorado") no parece proceder de la misma barrera de donde se obtiene la arcilla de las tres muestras correspondientes a los fragmentos en "verde y manganeso", por lo que se puede considerar alóctona o procedente de otra barrera. Sin embargo, la composición mineralógica encontrada en esta muestra no descarta que haya podido ser extraída de áreas más o menos próximas al lugar de Calatrava la Vieja. Lo que sí parece claro es que parece proceder de la misma cuenca del Guadiana y no de otras áreas peninsulares más meridionales.

Por otro lado, las muestras CV-I, CV-2 y CV-3 sí que se pueden considerar idénticas a las muestras estudiadas en un anterior trabajo sobre las cerámicas de Calatrava la Vieja (ZOZAYA; RETUERCE \& APARICIO, 1995).

\section{Yacimiento: Alarcos (Ciudad Real)}

Se han estudiado tres muestras de cerámica con decoración en "verde y manganeso" de época almohade procedentes de este yacimiento muy próximo al de Calatrava la Vieja.

\section{Descripción de las muestras:}

Al- I25: Clastos de cuarzo con $\varnothing \max =0,15 \mathrm{~mm}$. abundantes (40\%) hasta un $\varnothing \max =0,5 \mathrm{~mm}$. Aciculas de biotita (5\%), con $L \max =0,2 \mathrm{~mm}$. y de moscovita (5\%) con Lmax $=0,2 \mathrm{~mm}$. Un fragmento de esquisto biotítico de $1 \mathrm{~mm}$. Fragmentos cerámicos del mismo tipo al de la muestra (retrabajados).

Pasta arcillosa microcristalina algo oxidada (60\%-50\%).

Al-39 13-25: Similar a la muestra Al- 225. Cristales (clastos) de cuarzo (30-40\%) en $\varnothing m=0,12 \mathrm{~mm}$. Moscovita $(<5 \%)$ con $L \max =0,1 \mathrm{~mm}$. Las aciculas de biotita son escasas $(<2 \%)$ con $L \max =0,2 \mathrm{~mm}$. Fragmentos de pizarras y cuarcitas $(\varnothing \max =$ $0,3 \mathrm{~mm})$.

La pasta es arcillosa criptocristalina (60\%).

Al-32 I I: Cuarzo (30\%) con $\varnothing m=0,12$ y $\varnothing \max =0,30$ $\mathrm{mm}$. Aciculas de moscovita de hasta $L$ max $=0,5(10 \%)$, mas escasas de biotita $(<2 \%)$ con $\varnothing \mathrm{m}=0,15 \mathrm{~mm}$. Microfragmentos de cuarcita ( $\mathrm{I}$ ) y de pizarra (alguno alcanza los 2 $\mathrm{mm}$.).

Pasta arcillosa oxidada micro-criptocristalina (60-70). Se puede considerar similar a la muestra Al- 125.

Resumen. Las tres muestras de este yacimiento (Cerro Alarcos) presentan las mismas características y se pueden considerar autóctonas por su mineralogía. Pero por su composición y textura (fundamentalmente la pasta es mas gruesa y de tipo arenoso) son diferentes a las muestras procedentes de Calatrava la Vieja. En definitiva, las muestras procedentes de los dos vecinos yacimientos están elaboradas con materiales autóctonos a cada unos de ellos.

\section{Análisis Químicos}

Se han realizado determinaciones analíticas de las decoraciones, tipo "verde manganeso" y "reflejo dorado", de muestras de Calatrava La Vieja; utilizándose las muestras con las siglas CV-2 ("verde manganeso") y CV-4 ("reflejo dorado"). Para esta selección se tuvo en cuenta los datos mineralógicos previos que reflejaban características diferentes entre las muestras CV-I, CV-2, CV-3 (similares) y la CV-4.

Las técnicas usadas para las determinaciones fueron difractometrías de Rayos X y microscopía electrónica (energía dispersiva). 
Los difractogramas de Rayos $X$ realizados sobre las sustancias contenidas en las decoraciones de las muestras CV-2 (decoración en "verde manganeso") (Fig. 3 A) y CV-4 (decoración de "reflejo dorado") (Fig. 3 B) evidencian que se trata de un material no cristalino de sustancias amorfas con escasos cristales de cuarzo $(Q)$ y probablemente algún tipo de oxido de Fe (¿Hematites?).

Por energía dispersiva, en la muestra CV-2 se hicieron dos determinaciones sobre dos puntos y por orden de abundancia la composición es la siguiente: $\mathrm{SiO} 2, \mathrm{PbO}, \mathrm{As} 2 \mathrm{O} 3, \mathrm{CaO}$, $\mathrm{FeO}, \mathrm{K} 2 \mathrm{O}$. Los porcentajes de los elementos puede verse en las Tablas I y 2 :

$\begin{array}{ccc}\text { Elemento } & \text { \% Peso } & \text { \% Atómico } \\ \text { NaK } & 0,00 & 0,00 \\ \text { MgK } & 0,00 & 0,00 \\ \text { AlK } & 0,00 & 0,00 \\ \text { SiK } & 43,160 & 75,554 \\ \text { PbM } & 32,603 & 7,737 \\ \text { CIK } & 0,00 & 0,00 \\ \text { KK } & 0,978 & 1,23 \\ \text { SnL } & 4,019 & 1,665 \\ \text { CaK } & 1,646 & 2,019 \\ \text { FeK } & 1,119 & 0,985 \\ \text { AsK } & 16,475 & 10,811 \\ \text { Total: } & 100 & 100\end{array}$

Tabla I: Zaf Método de cuantificación de óxidos. Punto I de la muestra CV-2.

$\begin{array}{ccc}\text { Elemento } & \text { \% Peso } & \text { \% Atómico } \\ \text { NaK } & 0,00 & 0,00 \\ \text { MgK } & 0,00 & 0,00 \\ \text { AlK } & 0,00 & 0,00 \\ \text { SiK } & 43,095 & 75,398 \\ \text { PbM } & 32,846 & 7,790 \\ \text { CIK } & 0,00 & 0,00 \\ \text { K K } & 0,859 & 1,079 \\ \text { SnL } & 2,704 & 1,119 \\ \text { CaK } & 1,697 & 2,081 \\ \text { FeK } & 0,905 & 0,796 \\ \text { AsK } & 17,895 & 11,737 \\ \text { Total: } & 100 & 100\end{array}$

Tabla 2: Zaf Método de cuantificación de óxidos. Punto 2 de la muestra CV-2.

En la muestra CV-4 se realizaron igualmente dos determinaciones sobre dos puntos, presentando una composición de: $\mathrm{SiO} 2, \mathrm{PbO}, \mathrm{As} 2 \mathrm{O} 3, \mathrm{CaO}, \mathrm{SnO}, \mathrm{K} 2 \mathrm{O}, \mathrm{FeO}$ (de más a menos abundante). El Na aparece tan solo en uno de los puntos medidos y su presencia puede ser debida a una contaminación antrópica. Los porcentajes de los elementos pueden verse en las Tablas 3 y 4 :

$\begin{array}{ccc}\text { Elemento } & \text { \% Peso } & \text { \% Atómico } \\ \text { NaK } & 0,00 & 0,00 \\ \text { MgK } & 0,00 & 0,00 \\ \text { AlK } & 0,00 & 0,00 \\ \text { SiK } & 43,946 & 70,059 \\ \text { PbM } & 21,917 & 4,736 \\ \text { CIK } & 0,391 & 0,494 \\ \text { KK } & 1,17 & 1,34 \\ \text { SnL } & 4,34 & 1,637 \\ \text { CaK } & 8,928 & 9,974 \\ \text { FeK } & 1,077 & 0,863 \\ \text { AsK } & 18,232 & 10,896 \\ \text { Total: } & 100 & 100\end{array}$

Tabla 3: Zaf Método de cuantificación de óxidos. Punto I de la muestra CV-4.

$\begin{array}{ccc}\text { Elemento } & \text { \% Peso } & \text { \% Atómico } \\ \text { NaK } & 0,990 & 1,848 \\ \text { MgK } & 0,00 & 0,00 \\ \text { AlK } & 0,00 & 0,00 \\ \text { SiK } & 47,754 & 72,919 \\ \text { PbM } & 24,181 & 5,005 \\ \text { CIK } & 0,247 & 0,299 \\ \text { KK } & 1,802 & 1,977 \\ \text { SnL } & 3,399 & 1,228 \\ \text { CaK } & 8,356 & 8,941 \\ \text { FeK } & 0,958 & 0,736 \\ \text { AsK } & 12,313 & 7,048 \\ \text { Total: } & 100 & 100\end{array}$

Tabla 4: Zaf Método de cuantificación de óxidos. Punto 2 de la muestra CV-4.

\begin{abstract}
Los esmaltes aplicados en las muestras presentaban los mismos componentes pero mezclados en una diferentes proporción. Por otro lado, la fábrica o fábricas de procedencia de los esmaltes de la decoración de los fragmentos cerámicos analizados habría que localizarlos en unos lugares distintos a los de donde proceden las muestras. Probablemente, en puntos muy distantes de ellos. Este hecho es bastante evidente pues se necesitan yacimientos de donde extraer $\mathrm{Pb}$, Sn o As, que están ausentes de las explotaciones del área del Guadiana ${ }^{3}$, junto al que se localizan los dos enclaves que analizamos. Sin embargo, según se ha dicho con anterioridad, el soporte cerámico es local de los alrededores de ambos yacimientos arqueológicos: Calatrava la Vieja y Alarcos.
\end{abstract}

\section{Conclusiones}

En la comparación entre las muestras de los componentes de la decoración se aprecia una fuerte variación en los contenidos de Pb, Ca, As y menos fuerte en Si. Si bien en una apreciación visual pueden parecer similares, composicionalmente evidencian diferentes mezclas.

3 La zona más próxima donde se encuentran estos minerales es Sierra Morena ( $\mathrm{Pb}$ en el área de La Carolina, Sn y As en Almadén). 
Este hecho coincide con las diferencias observadas en términos mineralógicos entre las muestras CV-I, CV-2, CV-3 y CV-4, lo que puede confirmar la diferente "fabrica", "técnica" y "fabricante" de ambos tipos, aunque como ya se ha indicado también, y en función del material cerámico original, puede tratarse de una misma barrera -con la extracción efectuada en diferentes capas- 0 de otros más o menos próximos entre si.

En definitiva, los componentes mineralógicos de Calatrava y Alarcos son autóctonos de cada uno de los dos lugares. Si bien en Calatrava la Vieja se aprecian diferencias en las muestras, éstas pueden muy bien deberse al concreto punto de extracción de la propia barrera o proceder de otras barreras diferentes, más o menos próximas entre si y cercanas en todo caso a la propia ciudad. Por otro lado, aunque parece quedar claro que las arcillas son locales, los componentes de la decoración son traídos de otras áreas ajenas al río Guadiana medio.

\section{BIBLIOGRAFÍA}

ACIÉN ALMANSA, M.; alii ( 1995): "Evolución de los tipos cerámicos en el S.E. de Al-Andalus". 5e Colloque sur la Céramique Médiévale. Rabat, 1991. 125-I39.

ALARCOS (1995): Alarcos, I 195. El fiel de la balanza (Ciudad Real, 1995). Ed. Juan Zozaya. Toledo.

AZUAR RUIZ, R. (1989): Denia islámica. Arqueología y poblamiento. Alicante.

EL CORÁN (ed. 1986): Ed. Julio Cortés. Barcelona.

CARMONA ÁVILA, R. (1994): "Un alfar de época almohade en Madinat Baguh. Informe de los resultados de la intervención arqueológica de urgencia desarrollada en el solar de la c/ San Marcos, 20, 22 y 24 de Priego de Córdoba". Antiquitas, 5, 72-94.

CASTILLO ARMENTEROS, J. C. (|99|): "Excavación arqueológica de urgencia realizada en el solar sito entre las calles Alcázar-Altozano Dean Pérez de Vargas y Parras, de la localidad de Andújar (Jaén)". Anuario Arqueológico de Andalucía 1989. III. Actividades de Urgencia. Informes y Memorias, 276-29I.

CHAMPEAUX, G. y STERCKX, S. (1984): Introducción a los símbolos, Madrid

CHEVALIER, J. y GHEERBRANT, A. (|99|): Diccionario de los Símbolos. Barcelona.

ELIADE, M. (1964): Traité d'histoire des religions. París.

FERNÁNDEZ GABALDÓN, S. (1986): Las cerámicas almohades de Jerez de la Frontera (Calle de la Encarnación). Memoria de licenciatura. Universidad Autónoma de Madrid. Texto mecanografiado. Inédita. Madrid.

GISBERT SANTONIA, J. A. (1990): "Los hornos del alfar islámico de la Avda. Montgó/Calle Teulada. Casco urbano de Denia (Alicante). En: Fours de potiers et "testares" médiévaux en Méditerranée Occidentale, 75-91. Madrid.
JUAN, A. de; CABALLERO, A.; FERNÁNDEZ, M. (1995): "Alarcos medieval: la batalla de Alarcos". En: Alarcos, 1995, $4 \mid-60$.

JUAN, A. de, CABALLERO, A.; FERNÁNDEZ, M. (1996): "Alarcos: diez años de investigación arqueológica". En: Alarcos, I 1 95. Actas del congreso internacional conmemorativo del VIII centenario de la batalla de Alarcos. (Ciudad Real, 1995), 225-248. Ciudad Real.

LE VERT; LE BRUN (1995): Le vert et le brun. De Kairouan à Avignon, céramiques du Xe au XVe siècle. Marsella, 1995.

PUERTAS TRICAS, R. (1985): "Cerámica islámica en verde y morado de la alcazaba de Málaga". Cuadernos de la Alhambra, 21, 31-65.

RETUERCE VELASCO, M. (1995a): En: Alarcos, 1995.

RETUERCE VELASCO, M. (1995b): "La Meseta islámica como tierra de frontera". En: Alarcos, 1995, 81-99

RETUERCE VELASCO, M. (1996): "Documentación arqueológica de una ciudad almohade de la Meseta: Calatrava", Alarcos, 1 195. Actas del congreso internacional conmemorativo del VIII centenario de la batalla de Alarcos. (Ciudad Real, 1995), 21 I-222 Ciudad Real.

RETUERCE VELASCO, M. (1997a): La cerámica de la Meseta andalusí. (en prensa).

RETUERCE VELASCO, M. (1997b): Calatrava la Vieja I. La excavación arqueológica de la torre $n^{\circ} 27$. Junta de Comunidades de Castilla-La Mancha. (en prensa)

RETUERCE, M.; ZOZAYA, J. (1986): "Variantes geográficas de la cerámica omeya andalusí: los temas decorativos". En: La ceramica medievale nel Mediterraneo Occidentale. Siena-Faenza, 1984, 69-128. Florencia.

RONTOMÉ NOTARIO, E. (1995): En: Alarcos, 1995.

ROSELLÓ, E.; MORALES, A. (199I): "Calatrava la Vieja: Primer informe sobre la fauna de vertebrados recuperados en el yacimiento almohade. Tercera parte: peces", Boletín de Arqueología Medieval, 5, II3-133.

ROSSELLÓ BORDOY, G. (1978). Ensayo de sistematización de la cerámica árabe de Mallorca. Palma de Mallorca.

ROSSELLÓ BORDOY, G. (1987): "Algunas observaciones sobre la decoración cerámica en verde y manganeso", Cuadernos de Madinat al-Zahra, I, I25- 137.

THIRIOT, J. (1995): "Les ateliers". En: Le vert et le brun (1995): 19-40

V. AA. (1988): Arte, tecnología y literatura hispanomusulmanes, Il Jornadas de Cultura Islámica. (Teruel, 1988). Madrid.

W.AA. (1996): Ciudad Real y su provincia. 3 vol. Sevilla.

ZOZAYA, J.; RETUERCE, M.; APARICIO, A. (1995). "Cerámica andalusí de reflejo dorado: I 195- 1212", 5ème Colloque sur la Céramique Médiévale (Rabat, 1991). p. 121-124. Rabat. 


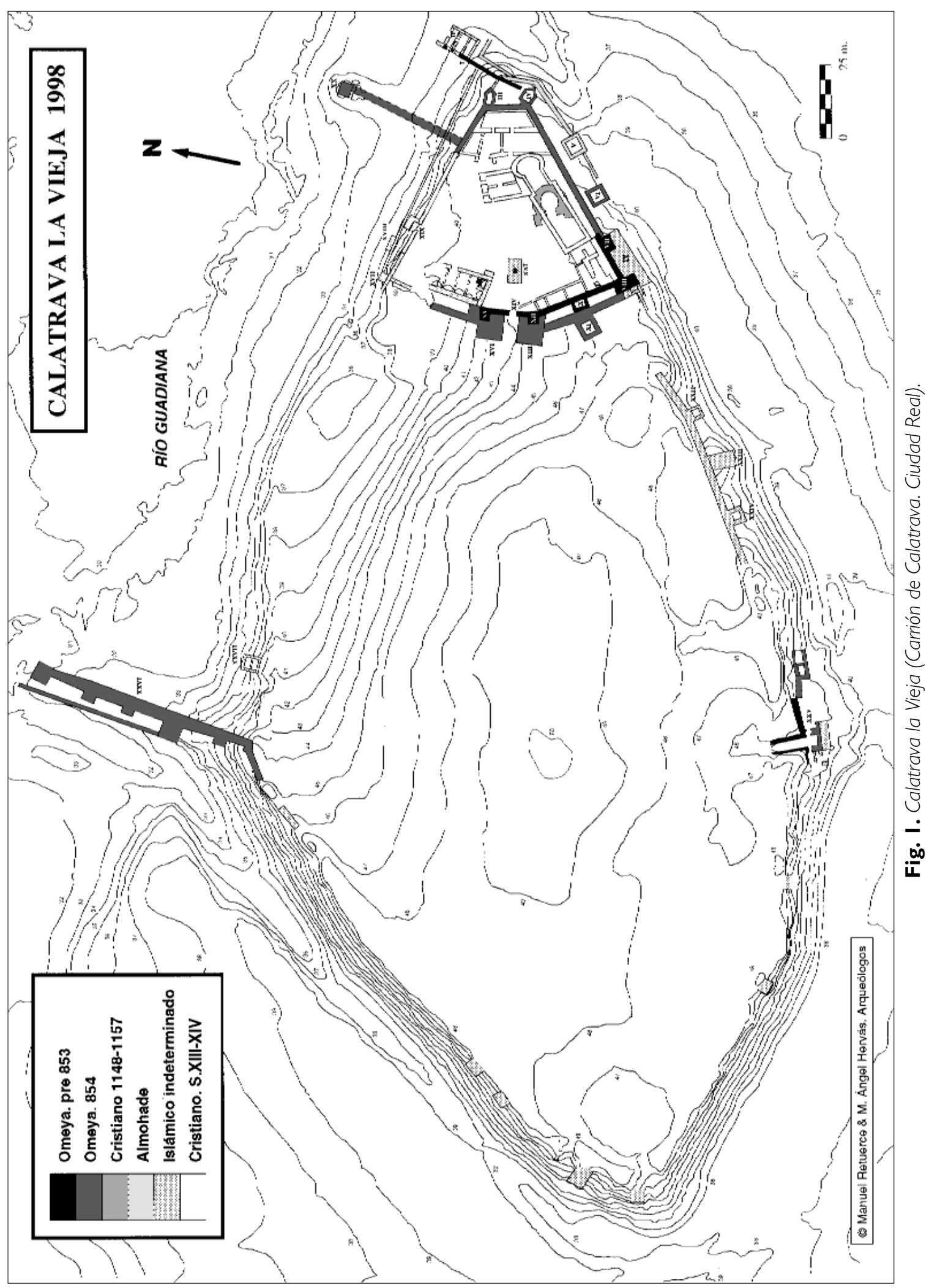



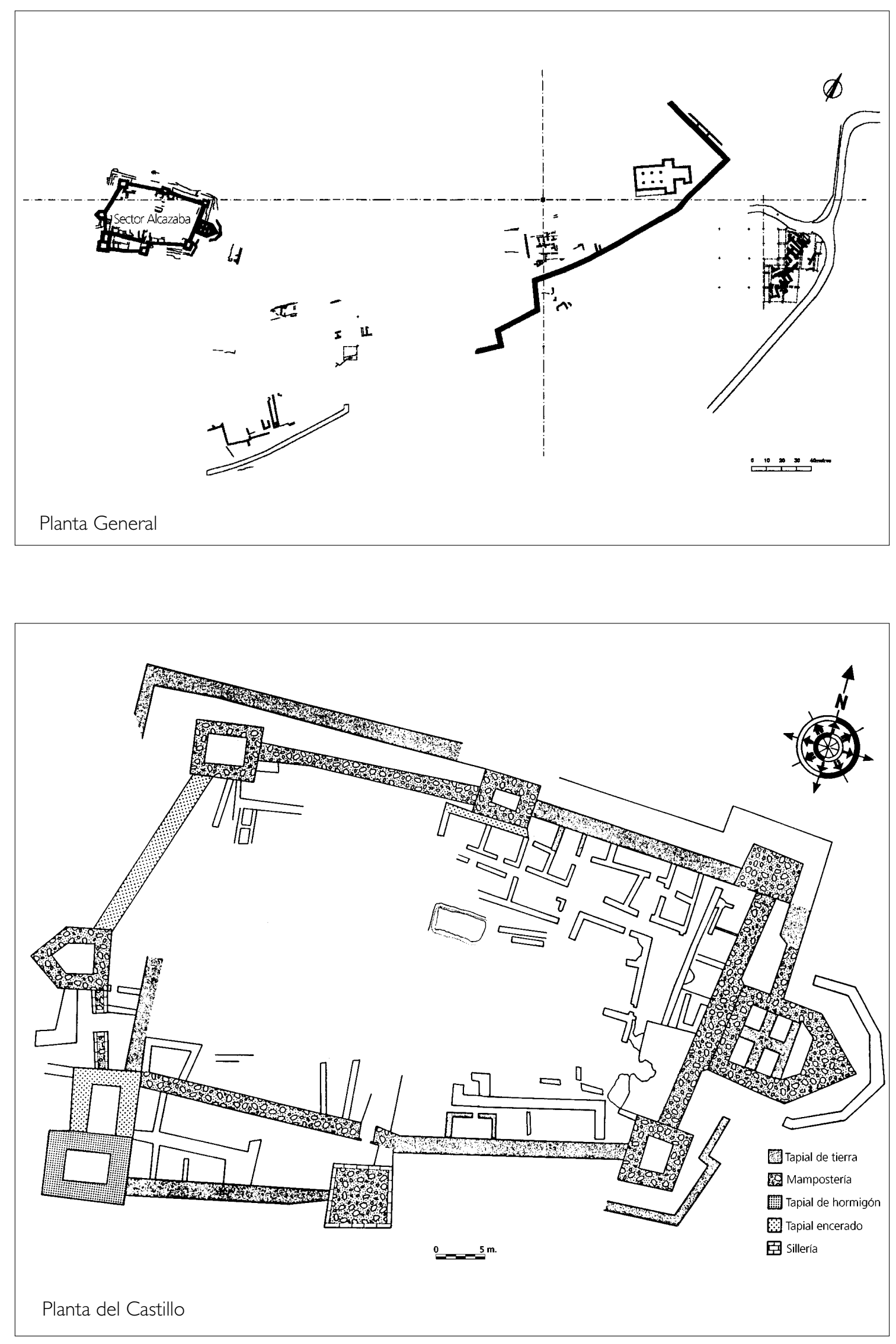

Fig. 2. Alarcos. (Ciudad Real). 


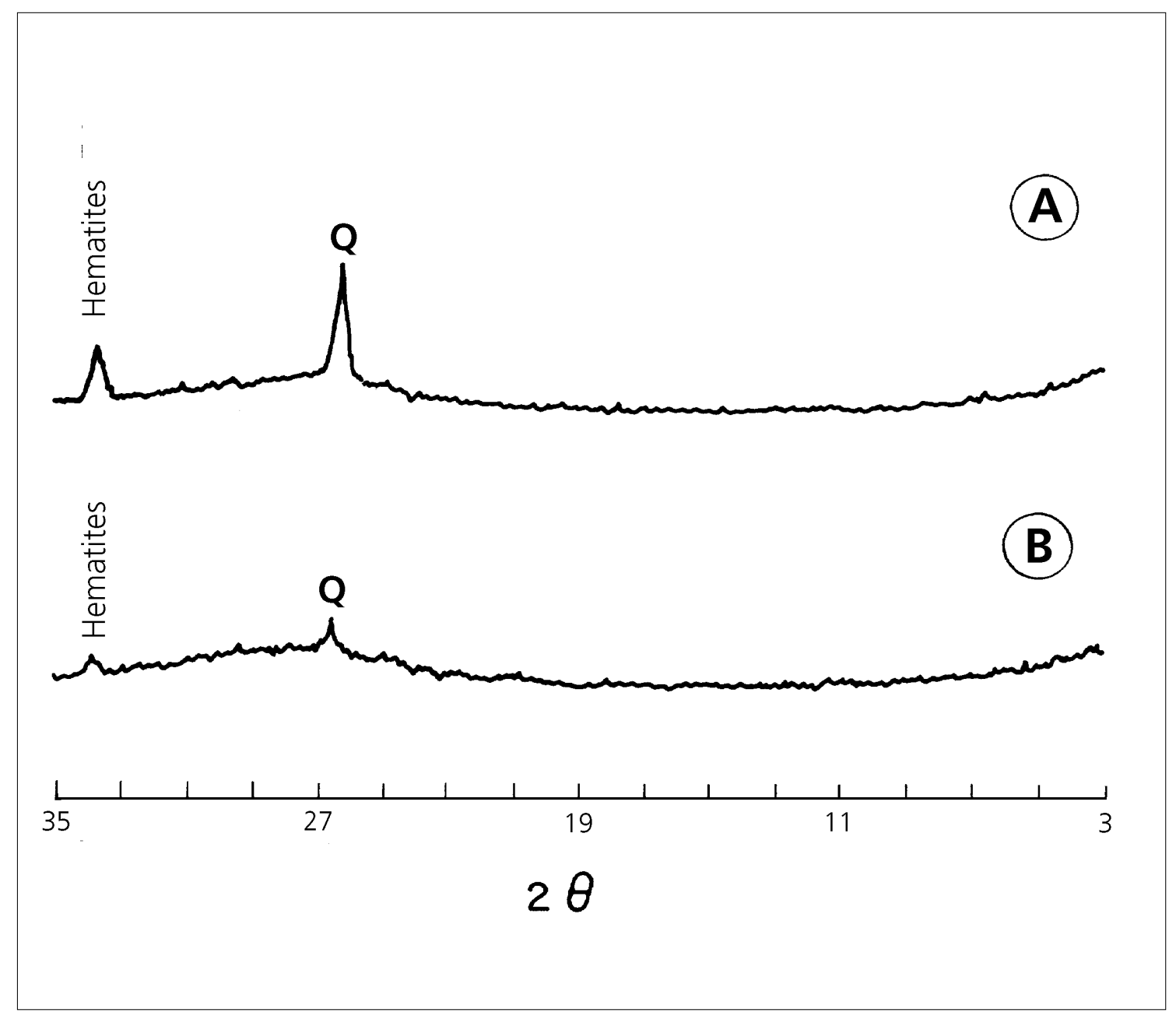

Fig. 3. Difractogramas de Rayos $X$ de las sustancias contenidas en las decoraciones de las muestras procedentes de Calatrava la Vieja. A: CV-2 ("verde y manganeso"). B: CV-4 ("reflejo dorado"). 


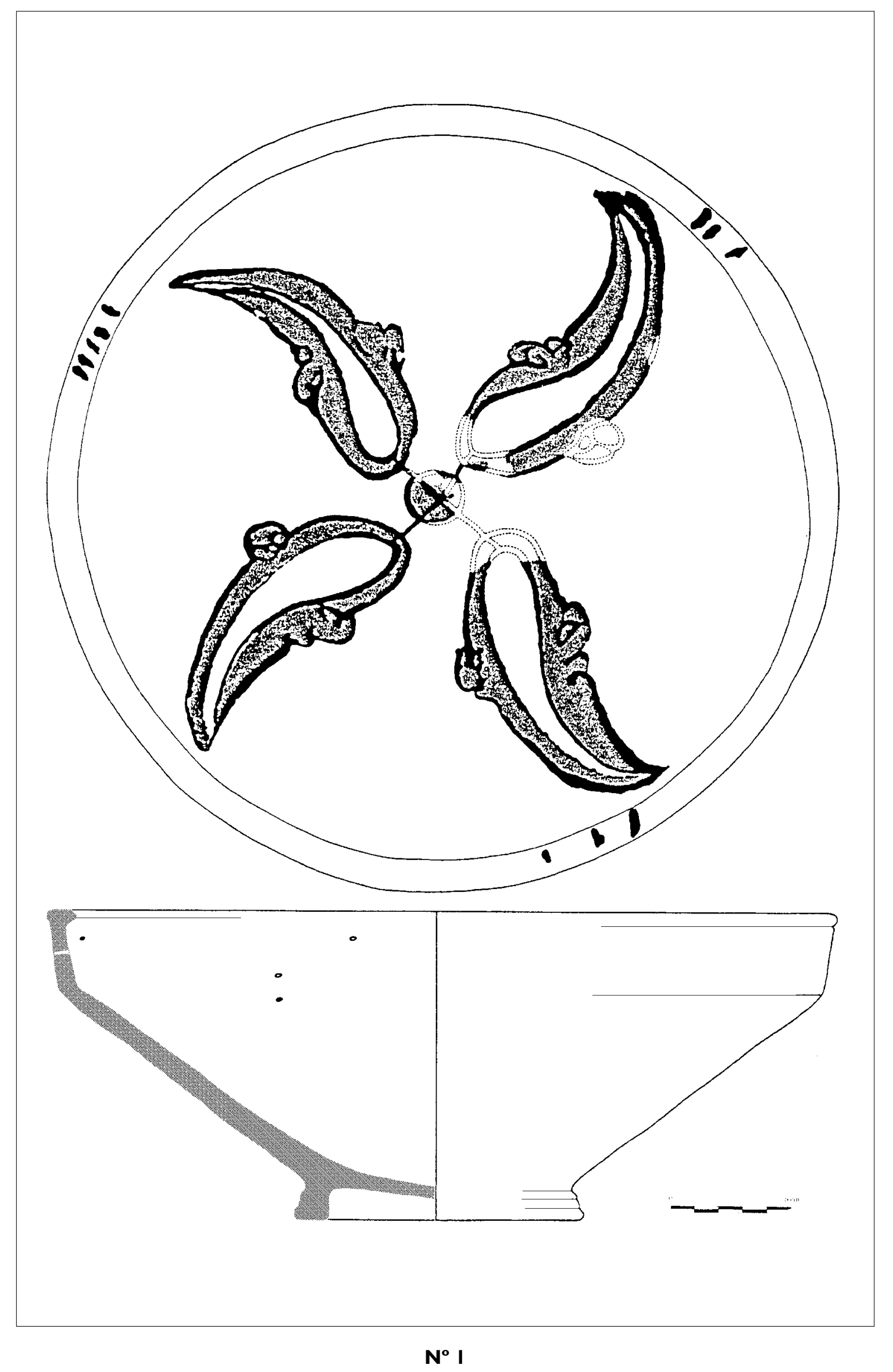




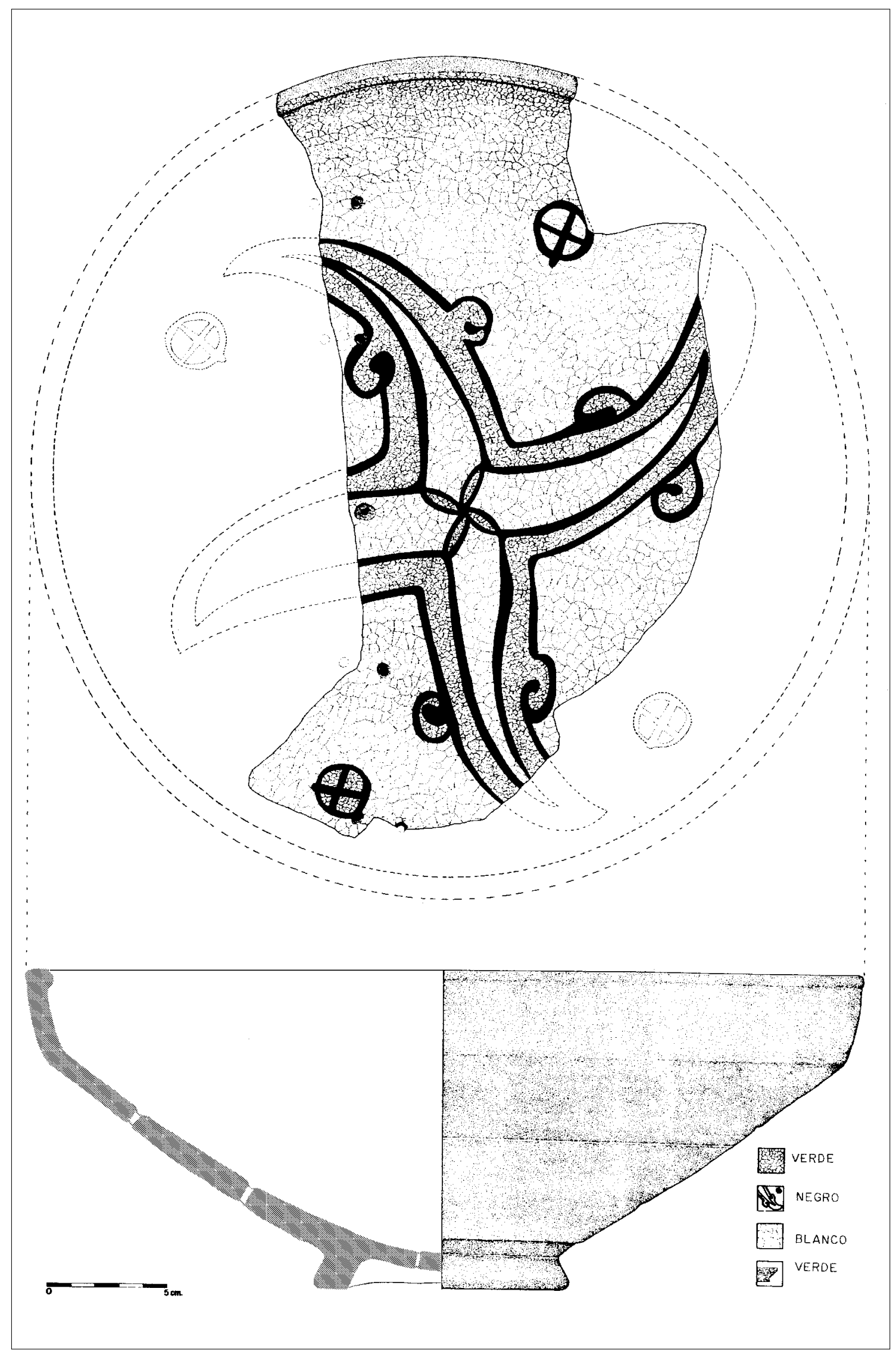

$\mathbf{N}^{\circ} \mathbf{2}$ 


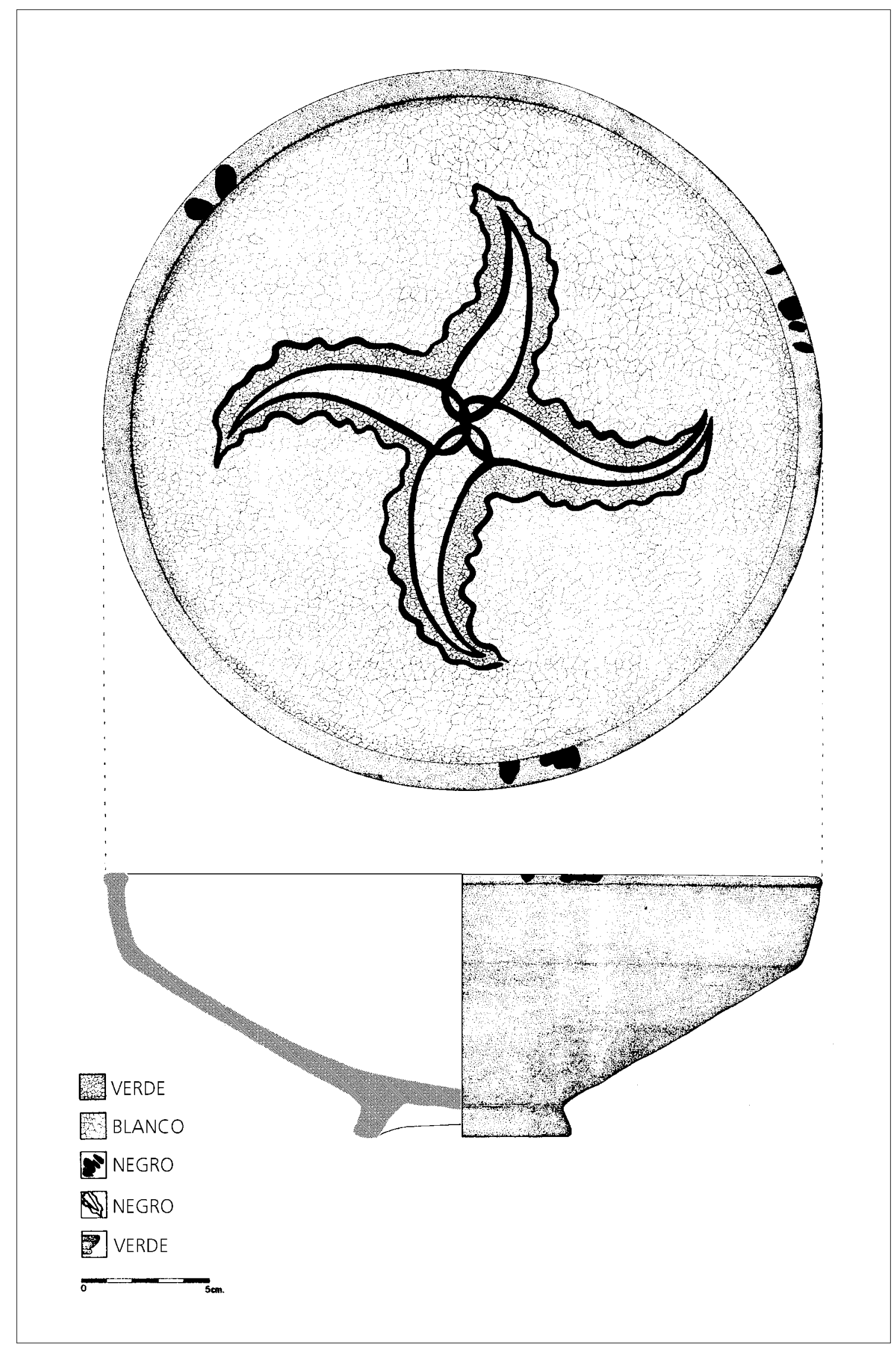

$\mathbf{N}^{\circ} 3$ 


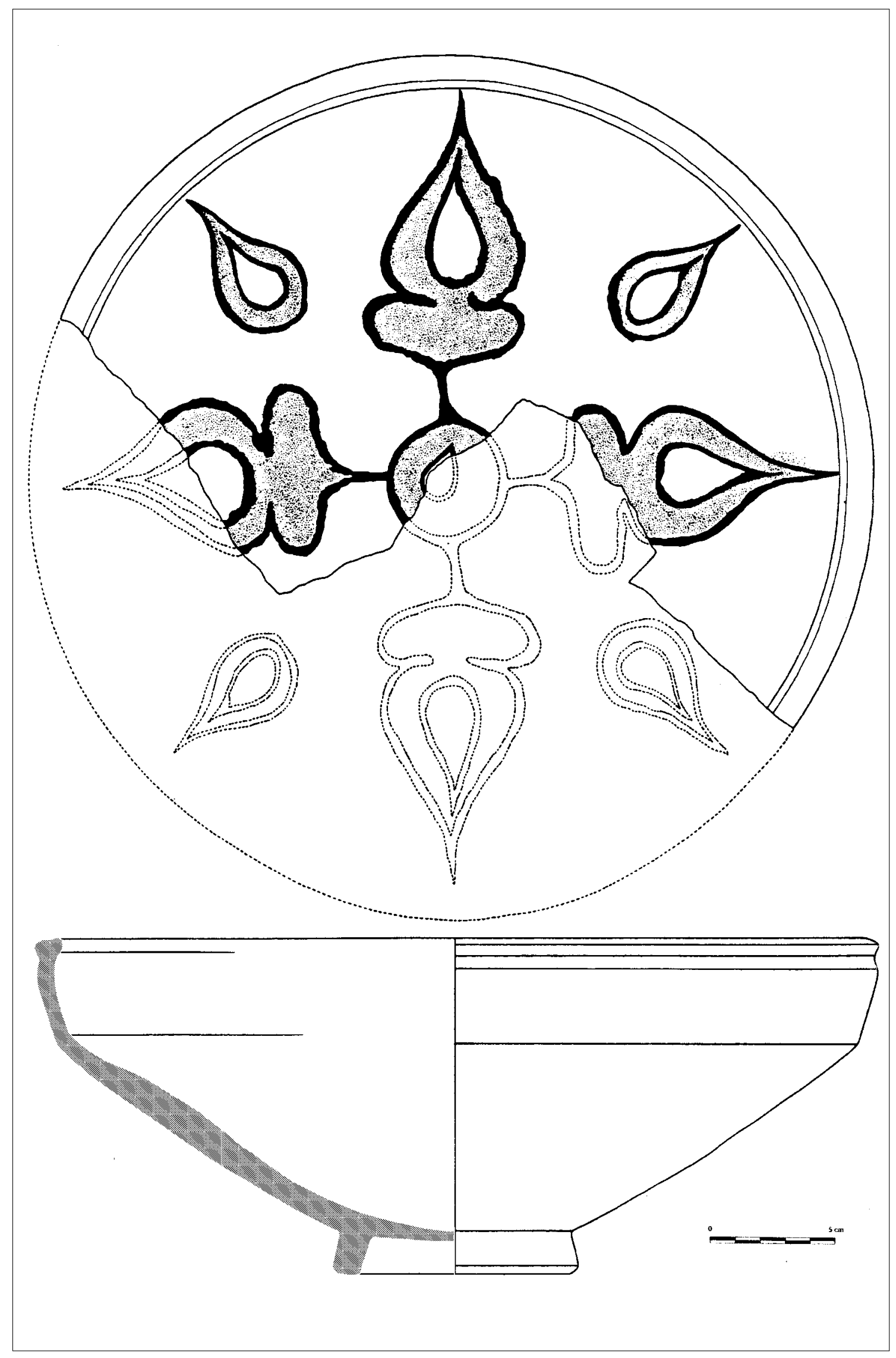

$N^{\circ} 4$ 


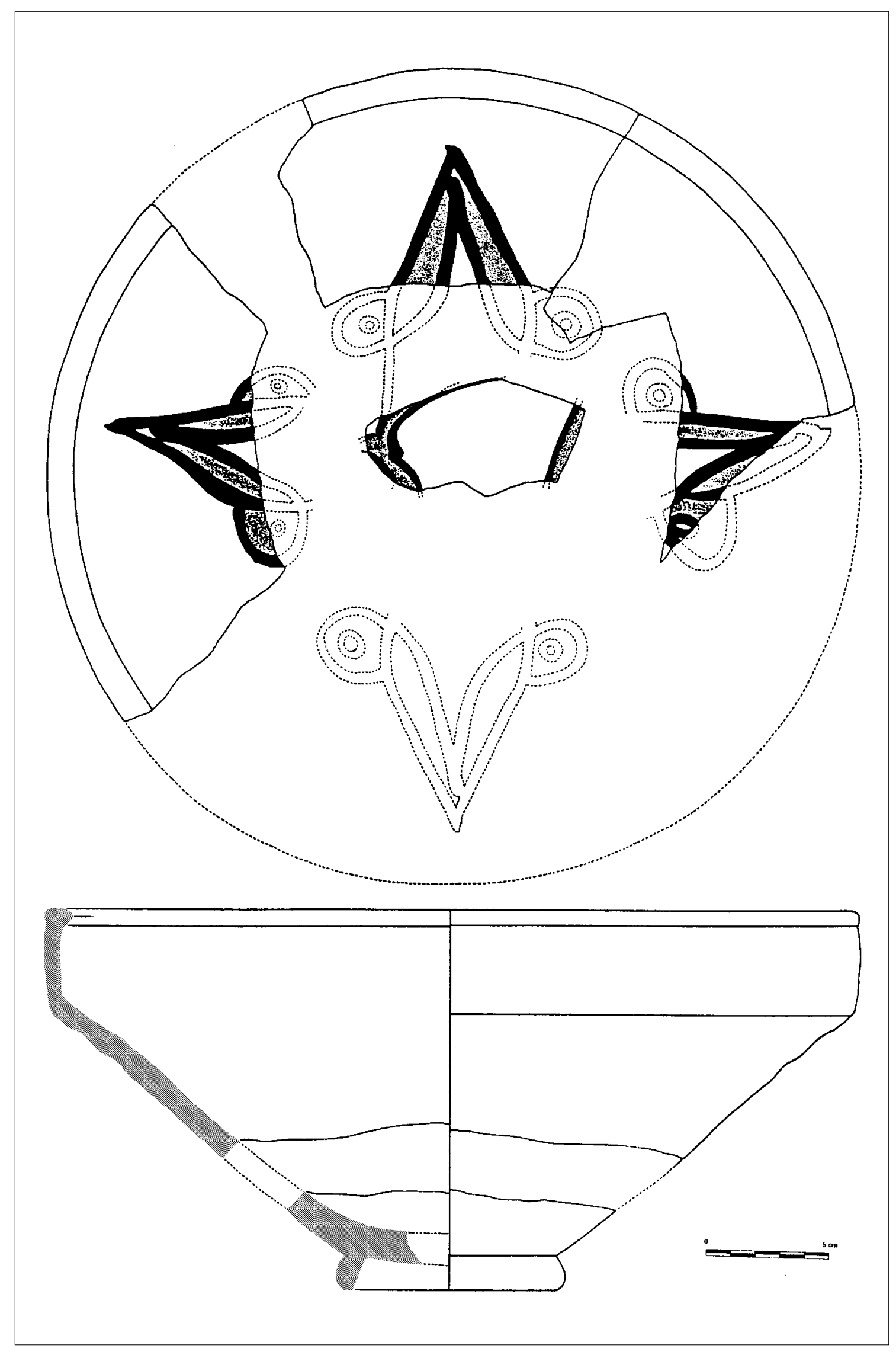

NN 5 


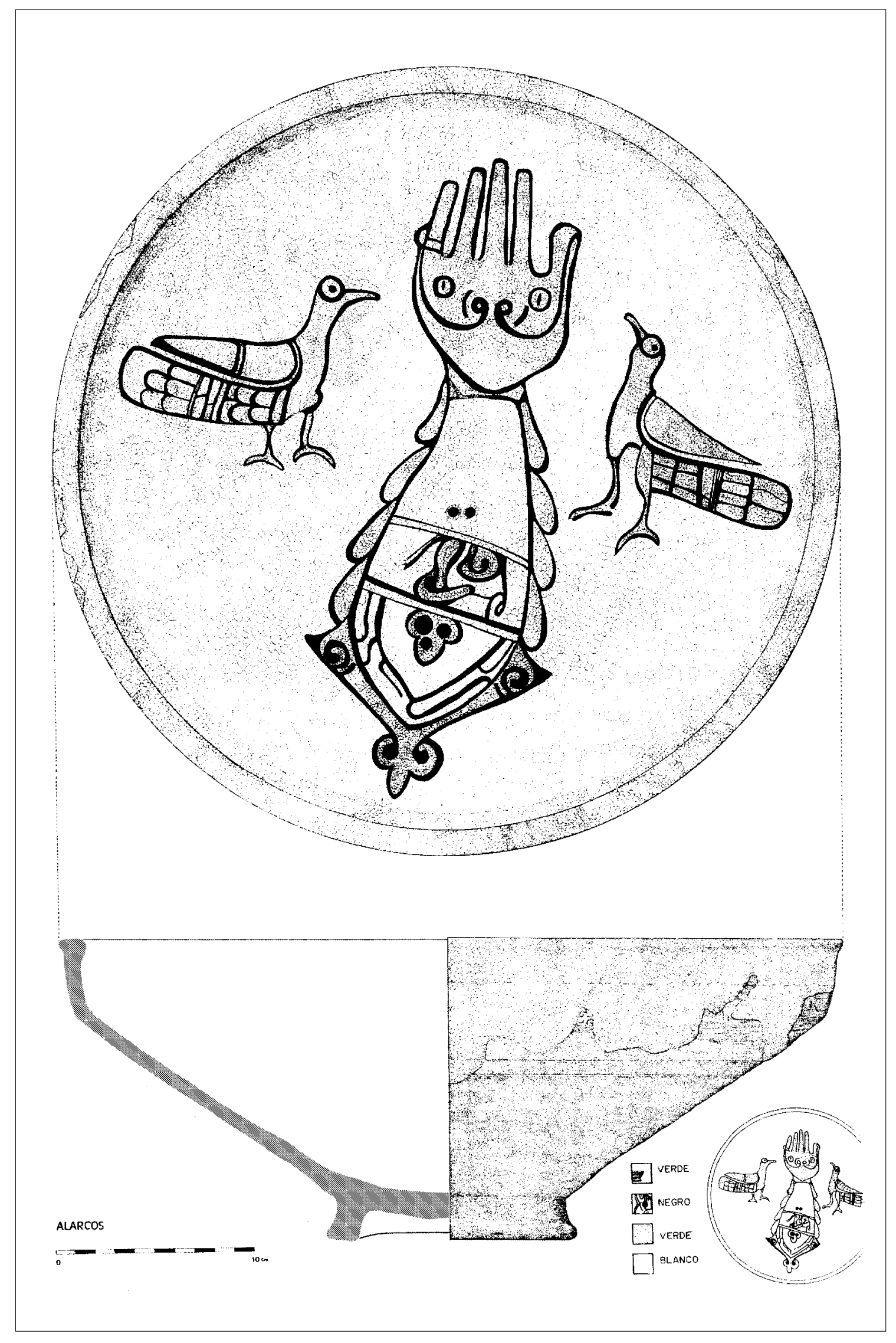

$N^{\circ} 6$ 